\title{
Preparation and Evaluation of a New Nano Pharmaceutical Excipients and Drug Delivery System Based in Polyvinylpyrrolidone and Silicate
}

\author{
Camila Braga Dornelas ${ }^{1,2}$; Alex Moura da Silva ${ }^{1}$, Cide Brizio Dantas ${ }^{1}$; Carlos Rangel Rodrigues ${ }^{1}$; Sandra Solange \\ Coutinho ; Plínio Cunha Sathler ; Helena Carla Castro ${ }^{3}$; Luiza Rosaria Sousa Dias ${ }^{4}$; Valéria Pereira de Sousa ${ }^{1}$ Lúcio \\ Mendes Cabral ${ }^{1}$. \\ ${ }^{1}$ Departamento de Medicamentos, Faculdade de Farmácia, UFRJ, Rio de Janeiro, RJ, Brazil. \\ ${ }^{2}$ Instituto de Macromoléculas Professora Eloisa Mano (IMA), UFRJ, Rio de Janeiro, RJ, Brazil. \\ ${ }^{3}$ LABioMol, Instituto de Biologia, UFF, Niterói, RJ, Brazil. \\ ${ }^{4}$ LQMed, Departamento de Tecnologia Farmacêutica, Faculdade de Farmácia, UFF, Niterói, RJ, Brazil.
}

Received, March 29, 2010; Revised, July 5, 2010; Accepted January 19, 2011; Published January 21, 2011.

\begin{abstract}
Purpose. The aim of this work is to prepare new nanocomposites based on a lamellar silicate alkyl ammonium montmorillonite (AAM) obtained by the intercalation of polyvinylpyrrolidone (PVP K-30) and glyceril monostearate (GME). Methods. AAM was characterized by XRD, TGA and DSC analysis and its compactation characteristics, functionality and toxicity were also tested. The AAM/PVP K-30 and AAM/GME nanocomposites were evaluated by XRD diffratograms to measure the interlamellar spacing values in order to prove the new nanocomposites formation. Tablets were prepared using methyldopa and theophylline as model drugs whereas the dissolution tests were carried out in simulated gastric and enteric fluids. Results. AAM showed a good compactability and compressibility characteristics for tablets preparation. The intercalation yields $(\sim 25 \%)$ of the nanocomposites were efficient. The AAM/PVP K-30 nanocomposites were successfully tested as dissolution enhancers and sustained release matrixes. Conclusions. The results suggest to the promising use of AAM (viscogel B8) and to the new nanocomposite prepared by clay/PVP K-30 intercalation as a new matrix for sustained release. These data also point to the feasibility of using these new nanocomposites as dissolution enhancer.
\end{abstract}

\section{INTRODUCTION}

The nanoscience and nanotechnology has been increasingly used in the search for new products and technologies, especially those of biomedical applications. Several studies have reported new nanobiomaterials and composites for modified release systems with several advantages compared with the isolated polymers or others pharmaceutical excipients (1-3).

According to the literature, the combination of polymeric materials as HPMC (hydroxypropyl methylcellulose) and PVP (polyvinylpyrrolidone) with inorganic silicate nanolamellae may provide new compounds named nanocomposites, which present more physically stability with improved properties for pharmaceutical purposes (i.e. compactability, solubility and other physical properties) compared with the initial materials. In this context, alkylammonium montmorillonite (AAM) that is an organophilic derivative of bentonite stands out due to its lamellar structure (4).
AAM presents parallel lamellae with internal anionic surfaces and organic interlamellar cations for equilibrium and stabilization of charges. Therefore, the intercalation process occurs when polymeric chains enter into the interlamellar space, increasing the network systems tortuosity and the water uptake of the new nanomaterial obtained. Therefore, the polymers intercalated in the clay can act as sustained release matrix.

The polymers may also be used as dissolution enhancer, either individually or in association with other substances. There is a direct relationship with the concentration used and the physicochemical properties and functionality of the polymer (5).

Correspondence Author: Dr. Lúcio Mendes Cabral; Departamento de Medicamentos, Faculdade de Farmácia, UFRJ, Prédio do CCS, Bloco K, $2^{\circ}$ andar, Sala 50, Ilha do Fundão 21941-590, Rio de Janeiro, Brazil. E-mail:1mcabral@pharma.ufrj.br 
At low concentrations, hydrophilic polymers such as PVP or cellulose derivatives may be used as dissolution enhancers (6) whereas in higher concentrations it may be also used as a sustained release matrix (7).

Due to these features, the polymer-silicate nanocomposites are interesting materials for producing modified release systems (8). Therefore, a promising alternative technology for the development of new excipients is the association of lamellar silicates as AAM with hydrophilic polymers, such as different molar masses PVP (i.e. PVP K-30, K-90) (9). In addition, to produce an erosive-lipophilic sustained release matrix, glyceryl monostearate (GME) can be intercalated into AAM nanolamellae producing a high tortuosity lipidic excipient. These approaches may generate hydrophilic-lipophilic combined systems, and a synergic combination for pharmaceutical technology purposes.

AAM presents a high tortuosity, moderate intumescence capacity and lipophilicity with low percentage of erosion. Therefore, the aim of this present work is to verify the use of lamellar silicate AAM as precursor of new pharmaceutical nanomaterials. On that purpose we studied the functionality of this silicate, the use as precursor for preparation of new nanocomposites (AAM/PVP and AAM/GME) with dissolution enhancer, and the drug release control properties. For the evaluation of these new excipients, two known model drugs were used including methyldopa, which presents low solubility in water (class II of BCS) and high instability due to oxidative processes (10), and theophylline for sustained release experiments due to its physicochemical properties (11). The study also compared the AAM and its nanocomposites with commonly used excipients, including HPMC $150000 \mathrm{cps}$, sodium lauryl sulphate (surfactant), croscarmellose sodium (superdisintegrant) (12), aerosil (silicates) (13), for different pharmacotechnical purposes.

\section{MATERIALS AND METHODS}

\section{Materials}

Microcrystalline cellulose (PH-102) (Avicel $\AA$; FMC, USA); methyldopa and theophylline (Farmex, México); croscarmellose sodium (Acdisol ${ }^{\circledR}$; FMC, USA); spray dried lactose monohydrate and lactose 200 mesh (Wyndale, New
Zeland); sodium lauryl sulphate (Merck, Germany); aerosil® 200 (Degusa, Germany); magnesium stearate (Mallinkrodt; Germany); hydroxypropyl methylcellulose 150.000 cps [PVP K-30] and glyceryl monostearate [GME] (Sigma, USA); alkylammonium montmorillonite [AAM] commercially known as viscogel $\mathrm{B} 8^{\circledR}$ (Bentec, Italy). We used purified water obtained from a Milli-Q system (Millipore, USA) in all solutions.

Statistic analysis pack (Statsoft Company, USA), pHmeter Orion (ION 450M) (Brazil), Erweka TBH 220 durometer (Germany), Sigma Centrifuge G-15, UV-Vis absorption spectrophotometer VARIAN 734S (USA), PerkinElmer DSC 7 (USA), Differential Scanning Calorimetry [DSC] and Thermogravimetric Analysis [TGA], Rigaku Miniflex X-ray diffractometer (Japan), Malvern Particle Size Analyzer MS2000 (United Kingdom), Shimadzu FTIR-8300 (Japan), scanning electron microscope (SEM) JEOL 1200EX (Japan).

\section{Evaluation of the Model Drugs}

Methyldopa and theophylline were characterized by X-ray diffractometry (XRD), the diffraction sweep angle of $1^{\circ}$ to $30^{\circ}$ was used to verify the material crystallinity, whereas particle size distribution was determined by dynamic light scattering analysis to evaluate the reproducibility of their physical-mechanical properties and their influence in the formulations dissolution rate.

\section{Characterization and Evaluation of the AAM Functionality}

The organic content of the AAM as well as the endothermic characteristics of this compound were determined by thermogravimetrical analysis (TGA) and differential scanning calorimetry (DSC). The samples were analyzed at nitrogen outflow of 22.5 $\mathrm{ml} \cdot \mathrm{min}^{-1}$ and heated from $0^{\circ} \mathrm{C}$ to $450^{\circ} \mathrm{C}\left(10^{\circ} \mathrm{C} \cdot \mathrm{min}^{-1}\right)$.

The AAM samples were analyzed by $\mathrm{X}$-ray diffractometry (operated at $30 \mathrm{kV}, 15 \mathrm{~mA}, 0.05$ $\mathrm{mm}, 1{ }^{\circ} \mathrm{C} / \mathrm{min}$, at room temperature) equipped with a $\mathrm{CuK}_{2}$ radiation as source (wavelength of 0.15418 $\mathrm{nm})$. To identify the interlamellae space the diffraction of $2 \phi$ scan between $1^{\circ}$ and $10^{\circ}$ was registered. The infrared analyses were carried out on Fourier-transformed infrared spectrophotometer (FT-IR). Scanning electron microscope (SEM) analyses were performed in an electronic 
transmission microscope to study AAM functionality with a vacuum system operating at $10^{-}$ ${ }^{4}$ torr. The samples were prepared in a volumetric flask dispersing a small powder quantity of AAM in water and sonicated for $5 \mathrm{~min}$. Then, the samples were sputter-coated with gold/palladium by vacuum evaporation.

\section{Toxicity Determination}

In accordance to the USP 31 (2008), the toxicity tests of AAM were performed in two groups of ten Swiss mice (20 g $\pm 2 \mathrm{~g}$ ) (14). Animals of the first group received $300 \mu \mathrm{l}$ solution $(10 \mathrm{~g} / \mathrm{Kg}$ dose of AAM diluted in purified water) administered orally using an oral cannula and were monitored during 14 days. Another group of ten mice was used as control.

\section{Study of Compaction Characteristics}

To evaluate the compaction property of the silicate AAM, the thickness and hardness of compacted tablets were measured and compared with HPMC. Each tablet weighing about $600 \mathrm{mg}$ (HPMC 150 $000 \mathrm{cps}$ or AAM) was prepared adding $0.5 \%$ of magnesium stearate at different compression pressures $(10,30,50,70$ and $90 \mathrm{MPa})$.

\section{Preparation of Nanocomposite AAM/ GME}

The nanocomposite AAM/ GME was obtained through solution technique $\left(\mathrm{CHCl}_{2}\right)$. The solution was magnetically stirred at room temperature and refluxed in different intercalation conditions (45 min and 12, 48 and $72 \mathrm{~h}$ at 1:1 AAM/GME mass ration). The material was centrifuged, filtrated and pulverized after drying. The final material from the reactions was characterized by a combination of different techniques, including X-ray diffractometry (XRD - operated at $30 \mathrm{kV}, 15 \mathrm{~mA}, 0.05 \mathrm{~mm}$, $1{ }^{\circ} \mathrm{C} / \mathrm{min}$, at room temperature), Fourier Transform Infrared (FTIR) spectrometry, analyses by gas chromatography (GC) and thermogravimetry (TGA and DSC). The intercalation yield was obtained by TGA analysis and gravimetric measurement. For TGA and DSC analysis, the samples were analyzed at nitrogen outflow of $22.5 \mathrm{ml} \cdot \mathrm{min}^{-1}$ and heated from $0^{\circ} \mathrm{C}$ to $450^{\circ} \mathrm{C}\left(10^{\circ} \mathrm{C} \cdot \mathrm{min}^{-1}\right)$. The start materials and their respective physical mixtures used in the reactions were used as controls for verifying nanocomposite formation.

Aiming to confirm the process yield, GC analysis was used to quantify volatile contents (octadecylamine and GME) in the nanocomposite and in the supernatant of the intercalation assays. Sample solutions were prepared at $5.0 \mathrm{mg} / \mathrm{ml}$ concentration by dissolving in $\mathrm{CHCl}_{2}$ (GME, octadecylamine and supernatant) and the material obtained by the filtration process. The analyses were carried out in triplicate using a capillary column with $30 \mathrm{~m}$ of length, $250 \mu \mathrm{m}$ diameter and $0.25 \mu \mathrm{m}$ of thickness film (Table 1). The initial temperature was set as $200^{\circ} \mathrm{C}$, reaching the maximum of $325^{\circ} \mathrm{C}$ in a period of $55 \mathrm{~min}$. An injection volume of $1.0 \mu \mathrm{l}$ was delivered using a $10.0 \mu \mathrm{l}$ syringe for detection by flame ionization.

\begin{tabular}{lclc}
\hline \multicolumn{3}{c}{ Table 1. Injector and column parameters for GC analysis } \\
\hline \multicolumn{2}{c}{ Injector split/splitless } & \multicolumn{2}{c}{ Capillary column } \\
\hline Mode & split & Length & $30.0 \mathrm{~m}$ \\
Initial temperature & $270{ }^{\circ} \mathrm{C}$ & Diameter & $250.0 \mu \mathrm{m}$ \\
Pressure & $12.8 \mathrm{psi}$ & Thickness of film & $0.25 \mu \mathrm{m}$ \\
Split rate & $20: 01$ & Mode & constant flow \\
Split flow & $16.0 \mathrm{ml} / \mathrm{min}$ & Initial flow & $0.8 \mathrm{ml} / \mathrm{min}$ \\
Total flow & $19.0 \mathrm{ml} / \mathrm{min}$ & Initial pressure & $12.8 \mathrm{psi}$ \\
Gas & helium & Average Speed & $35 \mathrm{~cm} / \mathrm{seg}$ \\
Flow & $20.0 \mathrm{ml} / \mathrm{min}$ & Entry & frontal \\
Time & $2.0 \mathrm{~min}$ & Output & MSD \\
& & Pressure output & vacuum \\
\hline
\end{tabular}




\section{Preparation of Organoclay Nanocomposites} AAM/PVP K-30

The experiments were performed using $\mathrm{CHCl}_{2}$ solution at room temperature and different proportions of PVP K-30 and AAM (2:1, 1:1 and $1: 2)$ with different intercalation times $(15,45 \mathrm{~min}$ and $1,12,24,48,72 \mathrm{~h})$ were evaluated. The nanocomposite was obtained by solvent evaporation under reduced pressure at $45^{\circ}$. Alternatively, the centrifugation at $4000 \mathrm{rpm}$ and drying (r.t.) may be used to separate non intercalated polymer for quantification of the process yield. The resultant nanocomposites were characterized by a combination of different techniques including X-ray diffractometry (XRD), Fourier Transform Infrared (FTIR) spectrometry and thermogravimetry (TGA) in the same conditions used to characterize the AAM/GME nanocomposites. The intercalation yield was obtained by TGA analysis and gravimetric measurement.

\section{Tablets Formulation}

Tablets of methyldopa, a model drug for evaluating the dissolution enhancer performance, were prepared by wet granulation (10). Due to its intense oxidation, we used a PVP K-30 $3.0 \% \quad$ w/v ethanol:water (70:30) solution, containing $0.1 \% \mathrm{w} / \mathrm{v}$ (relative to the total liquid volume) of sodium metabisuphite as granulation liquid (15). The formulation base proposed in this study is shown in Table 2. All tablets were analyzed according USP 31 (14).

In the study of new sustained release excipients, tablets of theophylline were prepared by direct compression with matrix concentration of 10 to $40 \%$ relative to the total weight of the tablets (16). Additionally, $1.5 \%$ of magnesium stearate and quantity of lactose were also used to reach the final weight of $600 \mathrm{mg}$. The tablets hardness value measured for the sustained release formulation was between 80 and $90 \mathrm{~N}$. The tablets basic formulation is described in Table 3.

\section{Dissolution tests}

The evaluation of the dissolution of theophylline tablets (sustained release formulations) was performed using USP apparatus II (paddle), in 900 $\mathrm{ml}$ of dissolution media, at rotation of $50 \mathrm{rpm}$, with a constant temperature bath at $37 \pm 0.5^{\circ} \mathrm{C}$ (17). The dissolution media were $0.1 \mathrm{~N} \mathrm{HCl}, \mathrm{pH} \quad 1.2$ (simulated gastric fluid - SGF) and $\mathrm{pH} 6.8$ phosphate buffer solution (simulated enteric fluid SEF).

\begin{tabular}{lcc}
\hline \multicolumn{3}{l}{ Table 2. Tablets formulation for the evaluation of dissolution enhancers } \\
\hline Ingredients & Percent (\%) & Mass (mg) \\
\hline Methydopa & 38.0 & 250.0 \\
Lactose & 37.5 & 250.00 \\
Cellulose microcristalina & 19.0 & 125.00 \\
Dissolution enhancer (internal phase) ${ }^{1}$ & 0.5 & 3.13 \\
Crospovidone & 3.0 & 18.92 \\
Magnesium stearate & 1.5 & 6.31 \\
Dissolution enhancer (external phase) $^{1}$ & 0.5 & 3.16 \\
\hline${ }^{1}$ Nanomaterial (AAM/PVP K-30), sodium croscarmellose, aerosil and sodium lauryl \\
sulfate (SLS). The dissolution enhancer was used in the internal phase or external \\
phase.
\end{tabular}

\begin{tabular}{lcc}
\hline \multicolumn{3}{l}{ Table 3. Tablets formulation for the evaluation of sustained release matrices } \\
\hline Ingredients & Percent (\%) & Mass (mg) \\
\hline Theophylline & 16.67 & 100.0 \\
Lactose & 41.66 & 250.00 \\
Sustained release matrix ${ }^{1}$ & 40.00 & 240.00 \\
Magnesium stearate $^{1}$ HPMC 150.000 cps, AAM or nanomaterial (AAM/PVP K-30 or AAM/GME). \\
\hline
\end{tabular}


The evaluation of intercalation experiments using PVP K-30 and AAM were performed by solution technique. The dissolution samples were filtered with a $0.22 \mu \mathrm{m}$ PVDF filter before the analysis (17). The theophylline calibration curves in both gastric and enteric media were used to analysis by UV-spectrophotometry (16).

The dissolution tests for methyldopa formulations were performed using single point as described in the monograph of USP 31, using the apparatus II (paddle), in $900 \mathrm{ml}$ of dissolution media $(0.1 \mathrm{~N} \mathrm{HCl}, \mathrm{pH} \mathrm{1.2)}$, at rotation of $50 \mathrm{rpm}$, with a constant temperature bath at $37 \pm 0.5^{\circ} \mathrm{C}$. The value of $\mathrm{Q} \%$ stipulated was at least $80 \%$ after 20 min of dissolution. The quantification was carried out by UV-spectrophotometry using calibration curves in proper solvent (18).

The data obtained from the dissolution profile of theophylline were plotted according to the following equations that describe different release kinetics of the drug from matrices: zero order: $\% \mathrm{D}=$ $a_{1}+b_{1} . t$ (equation 1); first order: $\ln (100-\% D)=a_{2}$ - $b_{2} . t$ (equation 2); Higuchi: $\% D=a_{3}-b_{3} . t$ (equation 3) where $\% \mathrm{D}$ is the percentage of drug released at the time $t$ and $a_{1}, a_{2}, a_{3}, a_{4} ; b_{1}, b_{2}, b_{3}, b_{4}$ represent the intercepts and the slopes respectively. One-way ANOVA was used to evaluate the influence of different parameters on the release of the drug from the matrix.

The best plot data fit was obtained using these equations and observing the R-value (correlation coefficient obtained by linear regression). The dissolution data were also evaluated using the exponential equation: $M t / M_{\infty}=K t^{n}$ (19).

\section{RESULTS}

\section{Evaluation of the Model Drugs}

Methyldopa XRD analysis showed coarse crystal structure with no evident defined crystalline forms present in all samples tested in the same proportion (Figure 1). The coarse crystal form of this drug is the most commercialized probably due to its increased dissolution. The theophylline analysis showed no drug polymorphism (data not shown), only a crystalline monohydrate form, which suggested that there is no polymorphic form influence on active dissolution (20).

In accord to that proposed for direct compression active pharmaceutical ingredients, the mean diameter of the model drugs lots was $80 \mu \mathrm{m}$ and $100 \mu \mathrm{m}$ for methyldopa and theophylline, respectively, with low polydispersion index $(0.26$ and 0.38) in all samples tested.

\section{Characterization and Toxicity Evaluation of AAM}

In DSC/TGA analysis (Figure 2), AAM showed a mass decrease distributed in three steps including one related to water evaporation $\left(25-120^{\circ} \mathrm{C}\right)$ and other two related to salt degradation of octadecylamine $\left(120-520^{\circ} \mathrm{C}\right.$ and $\left.520-750^{\circ} \mathrm{C}\right)$. The XRD diffractogram of AAM revealed a peak corresponding to an interlayer space of $26.50 \AA$ as main characteristic (Figure 3). The spectrum of AAM showed axial deformation bands (in O-H $3446 \mathrm{~cm}^{-1}, \mathrm{C}-\mathrm{H}$ at $2962 \mathrm{~cm}^{-1}, \mathrm{CH}_{3}$ at 2924 and $2872 \mathrm{~cm}^{-1}$, and $\mathrm{CH}_{2}$ at $2853 \mathrm{~cm}^{-1}$ ) due to the presence of $\mathrm{C}_{18}$ alkyl chain, and a symmetric angular deformation band of $\mathrm{N}-\mathrm{H}$ in the region $1650-1580 \mathrm{~cm}^{-1}$ weak to strong intensity (data not shown). Five areas of the AAM morphology were analyzed by electronic transmission microscope (MET) (21) pointing to the presence of the lamellar structure initially proposed (Figure 4). Animals death was not observed after 14 days of exposure using $10 \mathrm{~g} / \mathrm{kg}$ of body weight fixed dose.

\section{Study of Compactation Characteristics}

We performed the hardness and thickness evaluation of AAM tablets in comparison with the HPMC using five different compression forces (Table 4). All tablets had $12 \mathrm{~mm}$ diameter and their thickness was measured by using a micrometer (Table 4). At the same pressure interval, the maximum hardness values of AAM were consistently greater than those of HPMC $(90 \mathrm{~N})$ reaching a maximum hardness at $195 \mathrm{~N}$, revealing an improved compression profile for silicate when compared to HPMC.

\section{AAM/GME Nanocomposite}

The aim of this proposal was to insert an excipient with lipophilic properties within the high tortuous AAM lamellae based on the compatibility of both materials. Our results showed no significant yield difference with time or temperature variations in the intercalation experiments $(p=0.0022)$. The yield measured by gravimetry, TGA and confirmed by $\mathrm{GC}$ analysis ranged from 22 to $27 \%$, and the ideal 
experimental condition was $12 \mathrm{~h}$ at room temperature, which reached $25 \%$ of intercalation yield.

The release of theophylline from the tablets was analyzed using the dissolution profile. Samples of $10 \mathrm{ml}$ were drawn each $10 \mathrm{~min}$ (SGF) or $20 \mathrm{~min}$ (SEF) and replenished with dissolution medium.

The XRD diffractogram showed an increase of $6.38 \AA$ in AAM interlamellae distance $(28.95 \AA$ versus $35.33 \AA$ ), which suggested intercalation of the material on the clay (Figure 5). The results of TGA/ DSC showed a shift of the GME endotherm, reinforcing the proposal of the interaction within the lamellae and the formation of a new material (Figure 6).

The permanence of the alkylammonium ion inside the clay lamellae and the intercalation agent content were determined by chromatography analysis of the supernatant. The presence of octadecylamine was not detected in the chromatograms of two supernatant samples (Figure 7). Thus, we discarded the possibility of competition between octadecylamine and GME groups. Furthermore, $25 \%$ of intercalation of GME was confirmed inside the AAM by GC analysis increasing the lipophilic character of this new nanoexcipient that can improve its sustained release properties when added with clay tortuosity.

\section{AAM/PVP K-30 Nanocomposite}

The nanocomposites were prepared based on different ratios (2:1, 1:1 and 1:2) of clay and polymers (AAM /PVP K-30) at different intercalation times $(15,30,45 \mathrm{~min}, 1,24,48$ and 72 h) in $\mathrm{CHCl}_{2}$ solution at room temperature without clay previous swelling. The nanocomposites obtained were evaluated to identify the interlamellar spacing values increase by XRD diffratograms (Table 5 and Figure 8).

Control intercalation tests (AAM and $\mathrm{CHCl}_{2}$ stirring at room temperature for $72 \mathrm{~h}$ ) were performed to verify the influence of intercalation conditions in the conformation structure inside the lamellae and the feasibility of increasing the interlamellae spacing. By using the XRD analysis, we verified that the effect of the solvent produced an important reduction of interlamellar spacing from $25.98 \AA$ to $21.82 \AA$. Considering this result, the increase of interlamellar spacing was even more significant (superior to $10 \AA$ ) and confirmed the intercalation process.
The TGA analysis of the intercalated PVPorganoclay material (Figure 9) determined under ideal process conditions, showed a yield of $27 \%$, $20 \%$ and $15 \%$ for a mass ratio of $2: 1,1: 1$ and $1: 2$, respectively. In the $2: 1$ system, the nanocomposite used in the sustained release studies due to the higher yield, it was observed a increase in the interlamellae spacing from $21.82 \AA$ (control) to $31.00 \AA$, in $15 \mathrm{~min}$ with stabilization after $45 \mathrm{~min}$ of intercalation reaction. Thus, as the other systems (1:1 and 1:2), the values obtained in the interlayer spacing were about $10 \AA$, with constancy after $1 \mathrm{~h}$.

\section{Evaluation of AAM and its Nanoderivatives as Sustained Release Matrix}

The studies of functionality of AAM included the determination of the percentage of theophylline release in SGF medium compared with tablets prepared with HPMC at different concentrations (Figure 10a and b). A remarkable initial burst effect was observed in the $10 \%$ of HPMC concentration in SGF (Figure 10 a), which was not observed with AAM at same concentration. The obtained values with $20 \%$ of HPMC and AAM concentration revealed similar release profile, despite of being statistically different $(\mathrm{p}<0.0001)$, with a lower release for AAM matrixes. We observed a drug release of $28.05 \%$ using AAM $40 \%$ with less efficiency in drug release delay compared to HPMC $(19.68 \%)$ matrix in the same concentration $(p=$ $0.0023)$.

The dissolution profile of theophylline in SEF was evaluated only using the best results of HPMC and AAM matrix concentrations (20 to $40 \%$ in weight) (Figure $10 \mathrm{~b}$ ). A lower burst effect was observed for AAM and HPMC at 20\%. Apparently AAM decrease the efficiency of the active release delay at $40 \%$ due to $\mathrm{pH}$ alteration. The HPMC concentration of $40 \%$ showed more efficiency in delaying the drug release $(\mathrm{p}=0.0015)$.

Therefore, in ideal intercalation conditions, we observed a higher drug retention capacity of the nanocomposite PVP/AAM in SGF (26\%) at 20\% matrix concentration than pure AAM (29.49\%), HPMC (40.23\%) and physical mixture (31.23\%) (p $=0.0096)$. Once again, the HPMC showed to be less efficient than AAM for controlling the theophylline release confirming the previous results (Figure 11). 


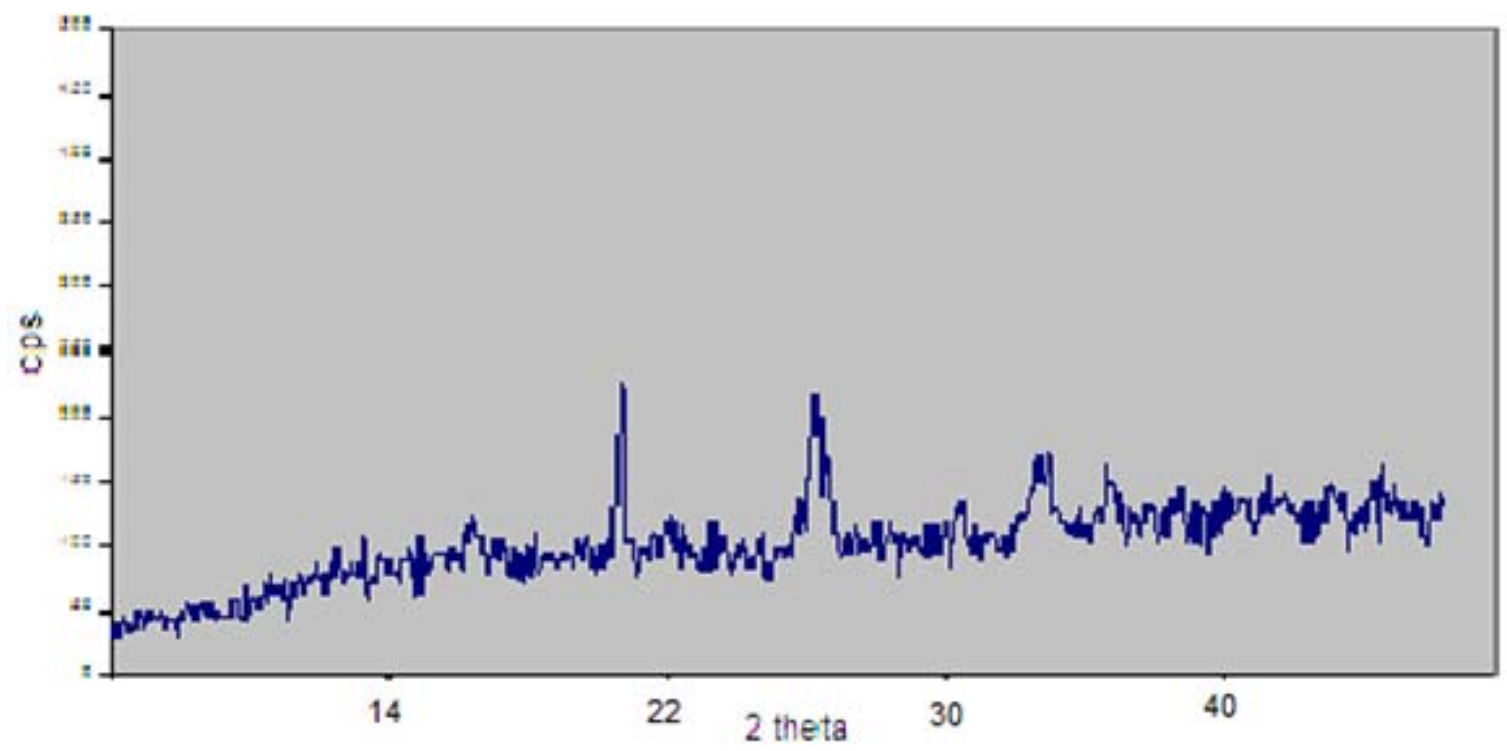

Figure 1. XRD diffractogram of methyldopa coarse crystal structure.

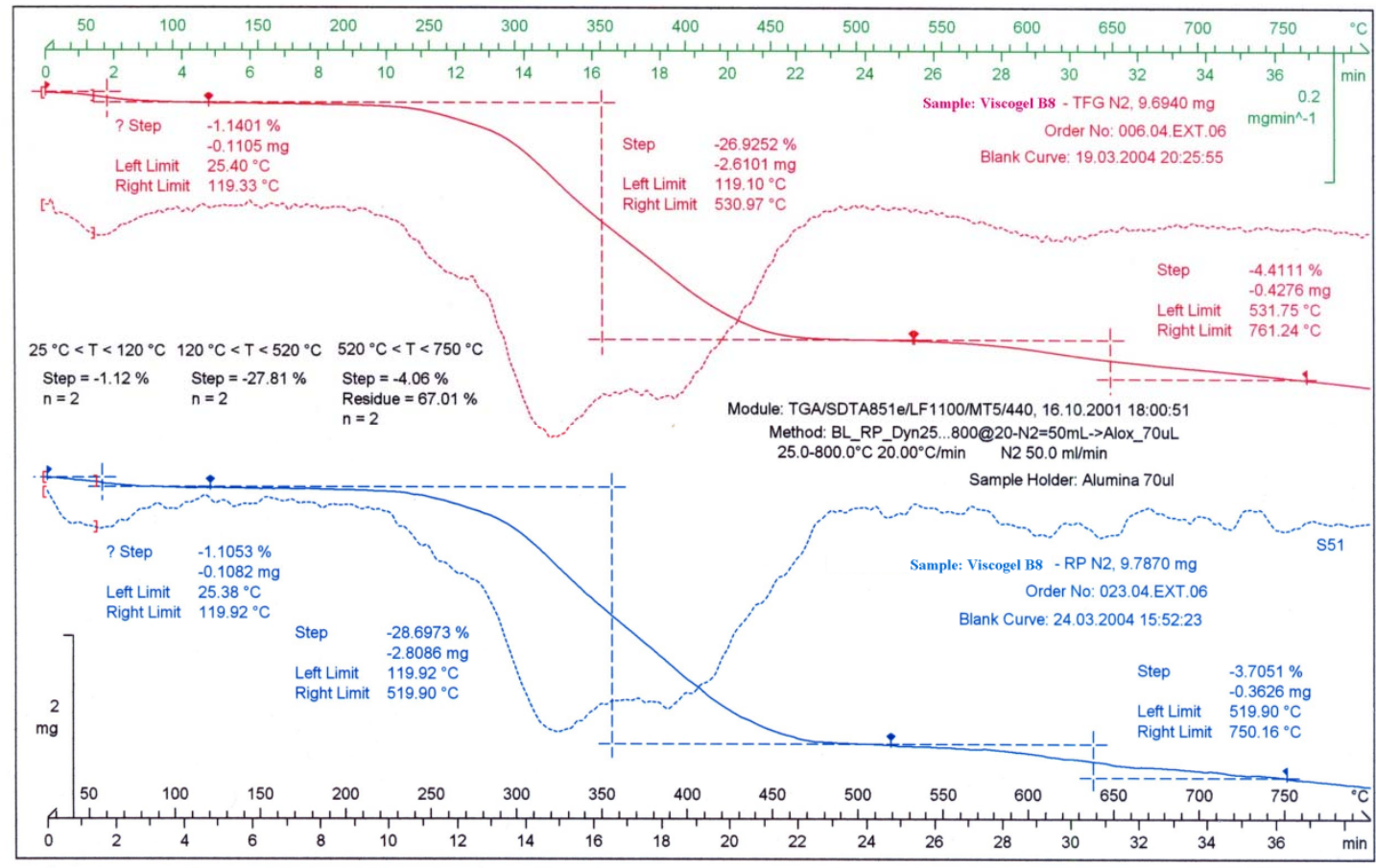

Figure 2. Thermogravimetric Analysis (TGA) and Differential Scanning Calorimetry (DSC) of two AAM samples. 


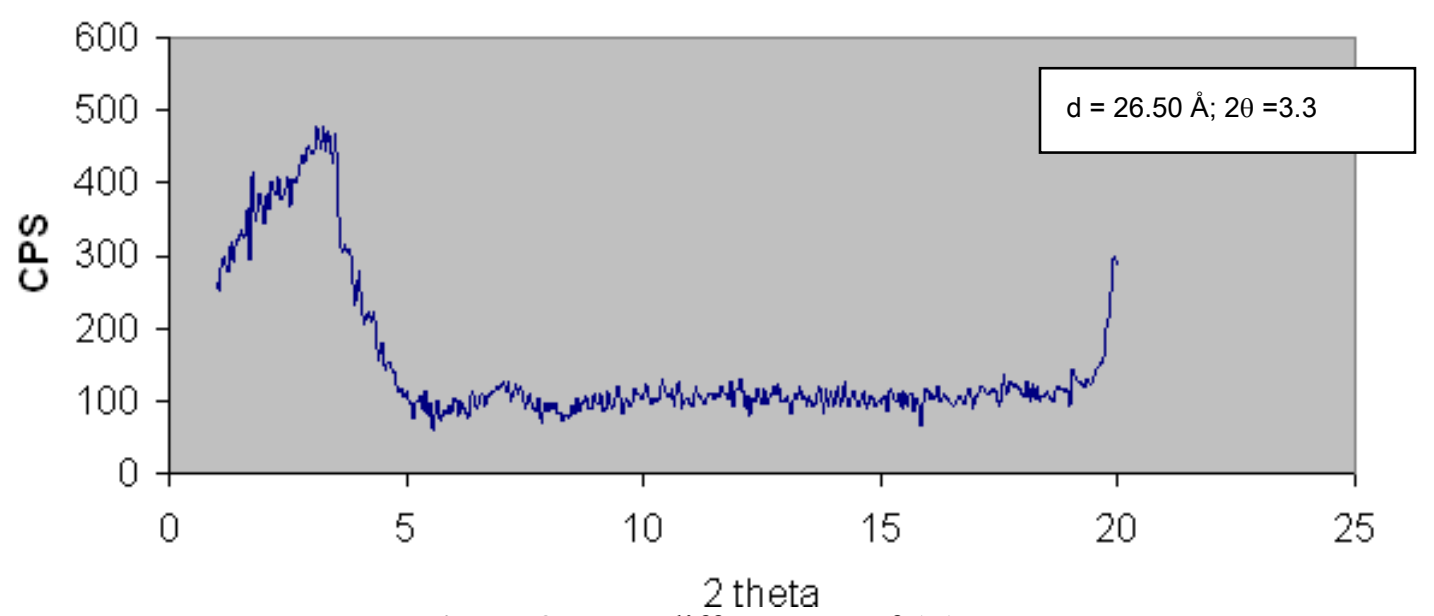

Figure 3. XRD diffratogram of AAM.

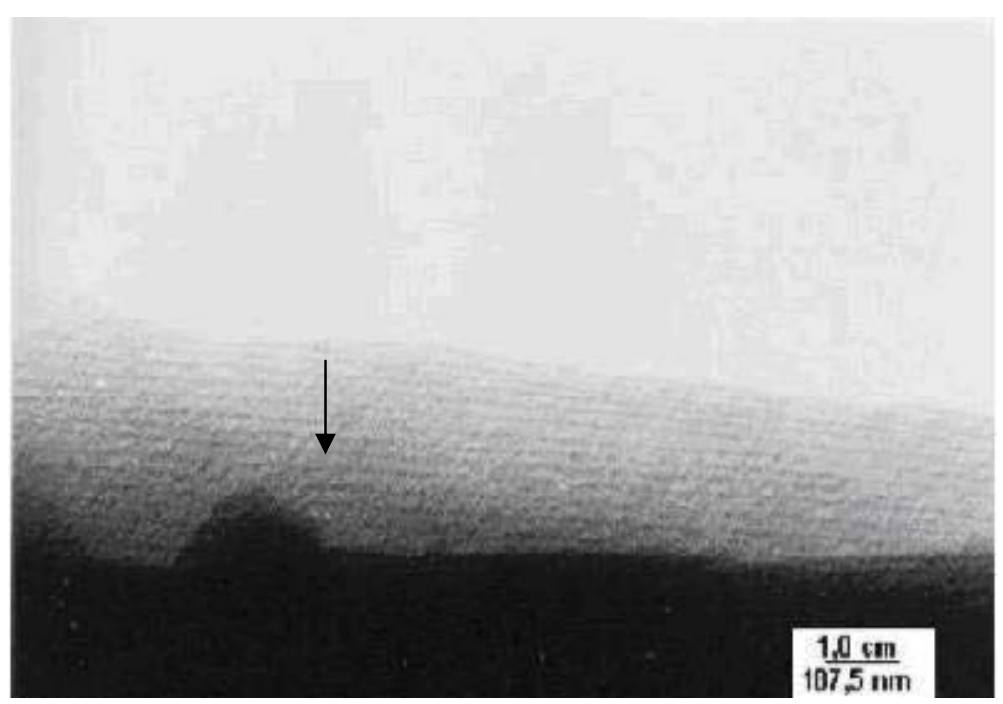

Figure 4. Electronic transmission microscope photomicrograph of the AAM with increase of $750000 \mathrm{X}$.

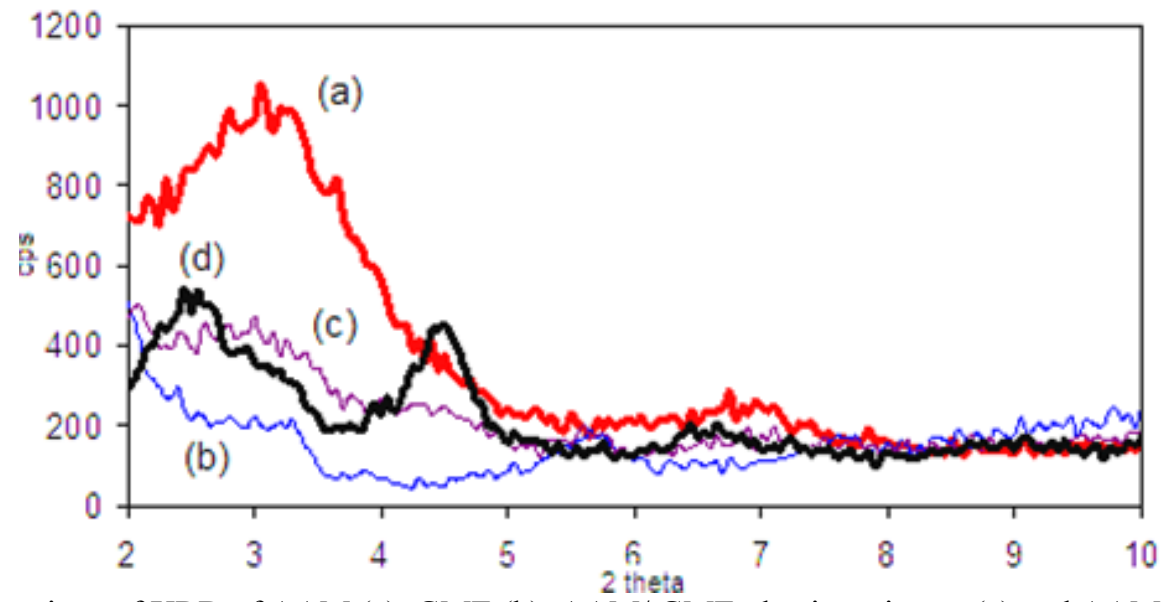

Figure 5. Comparison of XRD of AAM (a), GME (b), AAM/ GME physics mixture (c) and AAM/ GME intercalation (d). 


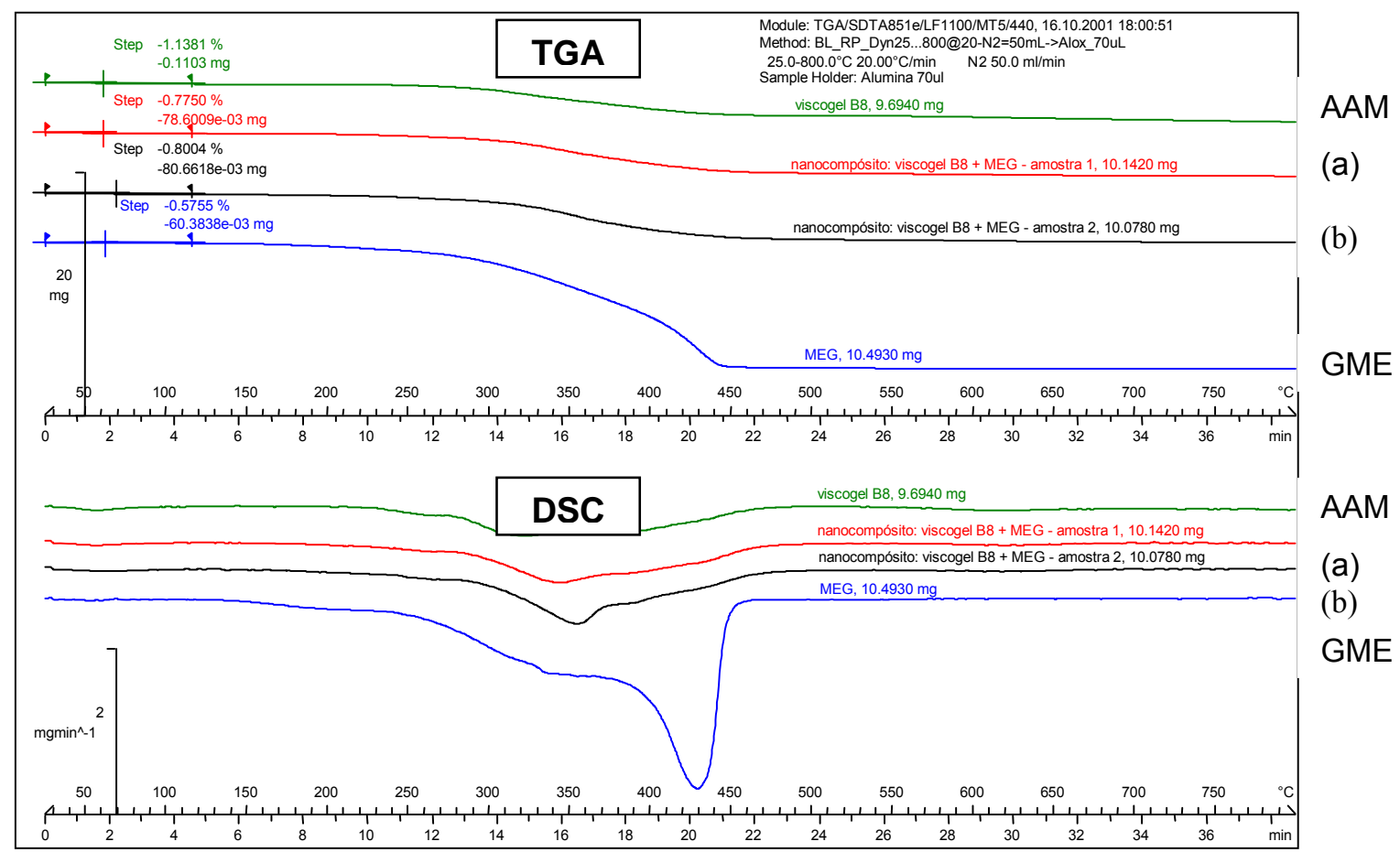

Figure 6. Thermogravimetric Analysis (TGA) and Differential Scanning Calorimetry (DSC) of AAM, GME and AAM/GME samples (a, b).

\begin{tabular}{ccccc}
\hline Table 4. Comparison of the compression characteristics for HPMC and AAM excipients \\
\cline { 2 - 5 } $\begin{array}{c}\text { Compression } \\
\text { pressure }\end{array}$ & \multicolumn{3}{c}{ HPMC } & \multicolumn{3}{c}{ AAM } \\
$(\mathrm{MPa})$ & $\begin{array}{c}\text { thickness } \\
(\mathrm{mm})\end{array}$ & $\begin{array}{c}\text { hardness } \\
(\mathrm{N})\end{array}$ & $\begin{array}{c}\text { thickness } \\
(\mathrm{mm})\end{array}$ & $\begin{array}{c}\text { hardness } \\
(\mathrm{N})\end{array}$ \\
\hline 64 & 6.7 & 20 & 4.3 & 120 \\
192 & 5.9 & 72 & 4.2 & 184 \\
319 & 5.6 & 82 & 4.1 & 184 \\
446 & 5.6 & 82 & 4.1 & 191 \\
574 & 5.6 & 90 & 4.1 & 195 \\
\hline
\end{tabular}

Table 5. Results of $2 \theta$ and interlayer spacing of the AAM/PVP K-30 nanocomposites in different proportions and reaction times

\begin{tabular}{ccccccc}
\hline & \multicolumn{2}{c}{ RATE } \\
$\mathbf{2 : 1}$ & \multicolumn{2}{c}{$\mathbf{1 : 1}$} & \multicolumn{2}{c}{$\mathbf{1 : 2}$} \\
\cline { 2 - 7 } Material & $\begin{array}{c}2 \theta \\
(\text { degree })\end{array}$ & $\begin{array}{c}\text { interlayer } \\
\text { spacing }(\AA)\end{array}$ & $\begin{array}{c}2 \theta \\
(\text { degree })\end{array}$ & $\begin{array}{c}\text { interlayer } \\
\text { spacing }(\AA)\end{array}$ & $\begin{array}{c}2 \theta \\
(\text { degree })\end{array}$ & $\begin{array}{c}\text { interlayer } \\
\text { spacing }(\AA)\end{array}$ \\
\hline AAM & 3.40 & 25.98 & 3.40 & 25.98 & 6.55 & 13.49 \\
(control) & 4.05 & 21.82 & 4.05 & 21.82 & 6.15 & 14.37 \\
$15 \mathrm{~min}$ & 2.85 & 31.00 & 2.55 & 34.65 & 3.40 & 25.99 \\
$30 \mathrm{~min}$ & 2.80 & 31.56 & 2.60 & 33.98 & 3.40 & 25.99 \\
$45 \mathrm{~min}$ & 2.70 & 32.72 & 3.10 & 28.50 & 3.50 & 25.24 \\
$1 \mathrm{~h}$ & 2.70 & 32.72 & 2.55 & 34.65 & 3.55 & 24.89 \\
$24 \mathrm{~h}$ & 2.60 & 33.98 & 2.60 & 33.98 & 3.20 & 27.61 \\
$48 \mathrm{~h}$ & 2.70 & 32.72 & 2.70 & 32.72 & 3.45 & 25.61 \\
$72 \mathrm{~h}$ & 2.70 & 32.72 & 2.70 & 32.72 & 3.32 & 26.61 \\
\hline
\end{tabular}



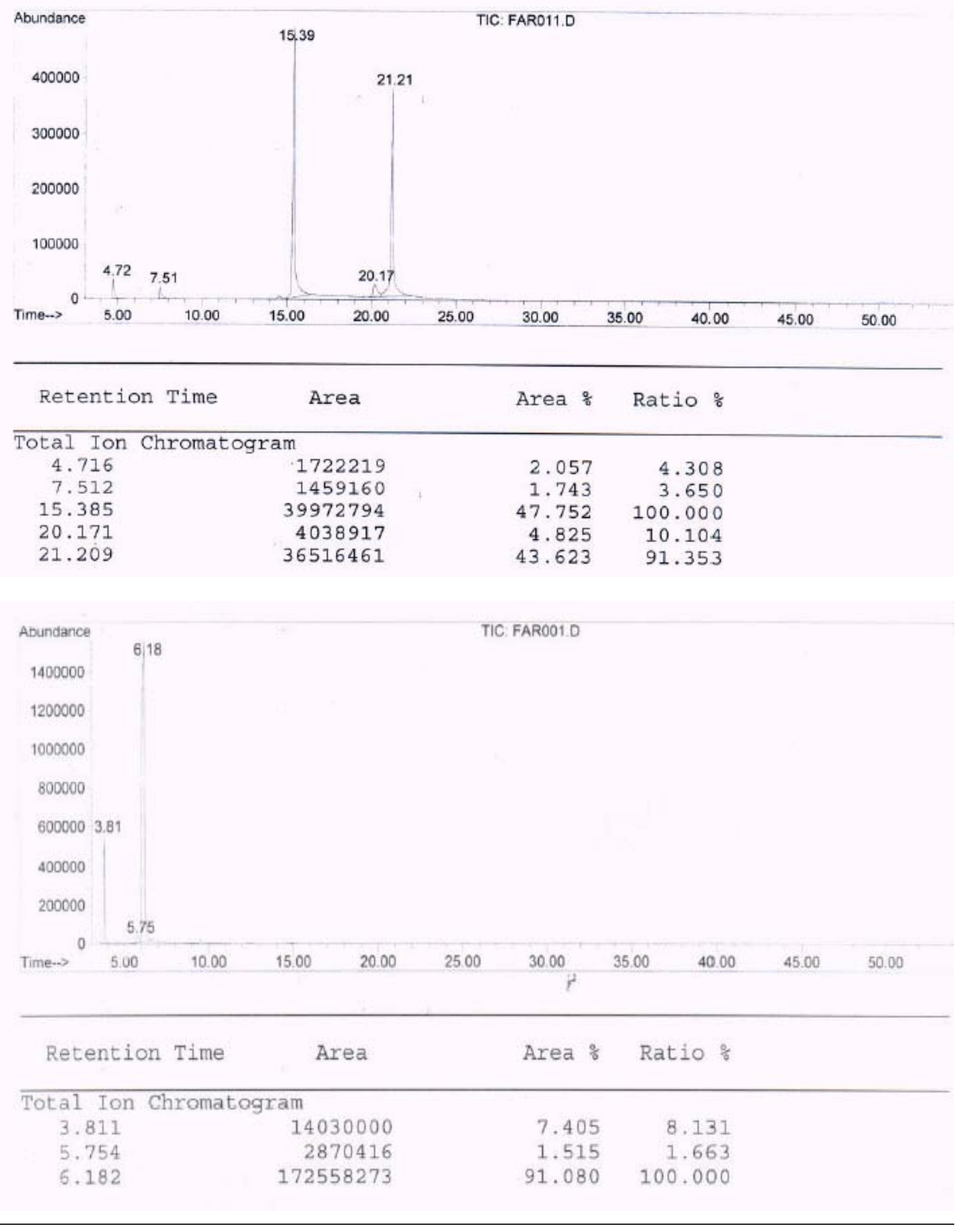

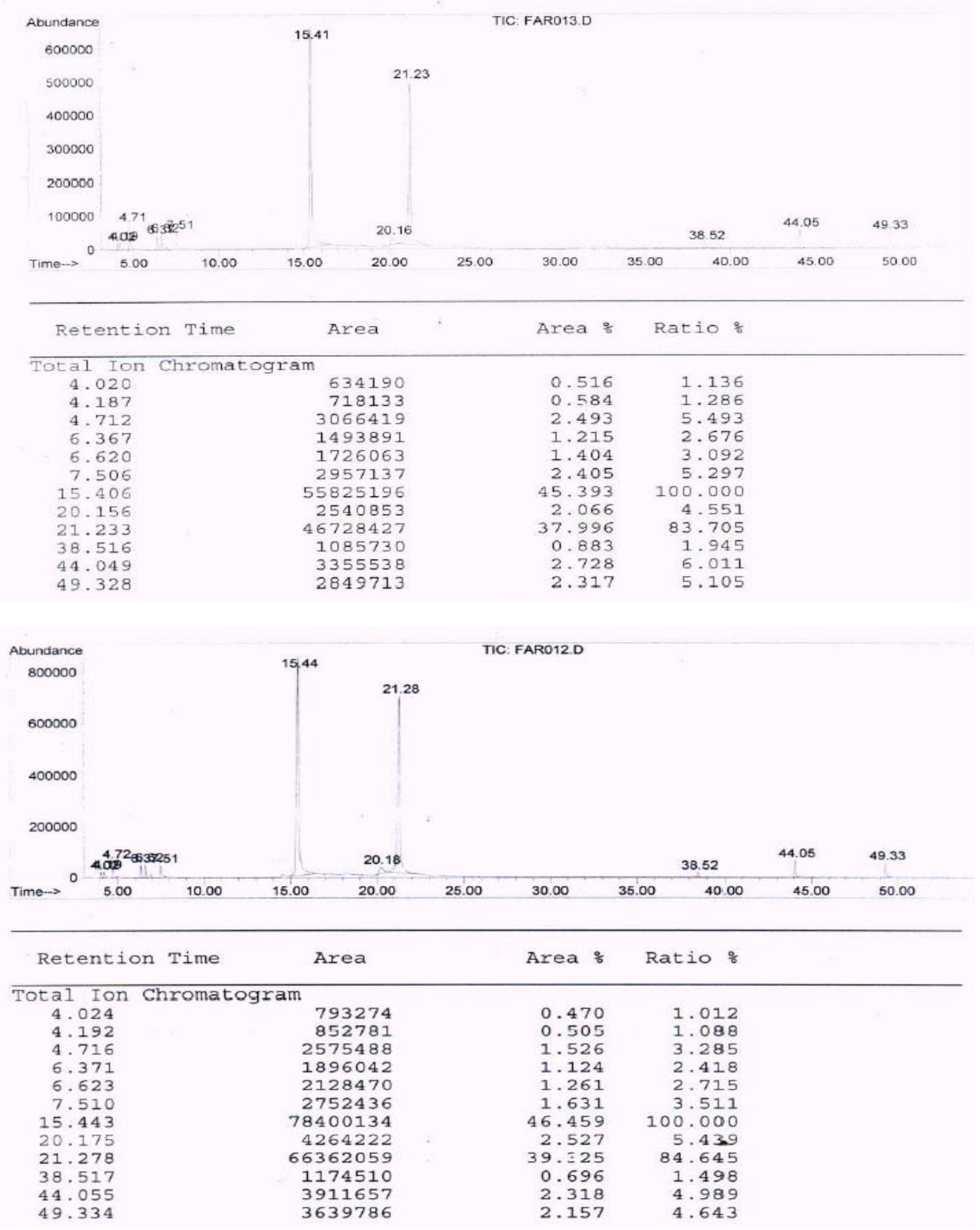

Figure 7. Analysis of GME and octabecylamine isolated, and two samples of the supernatant obtained by intercalation AAM/GME by gas chromatography. 

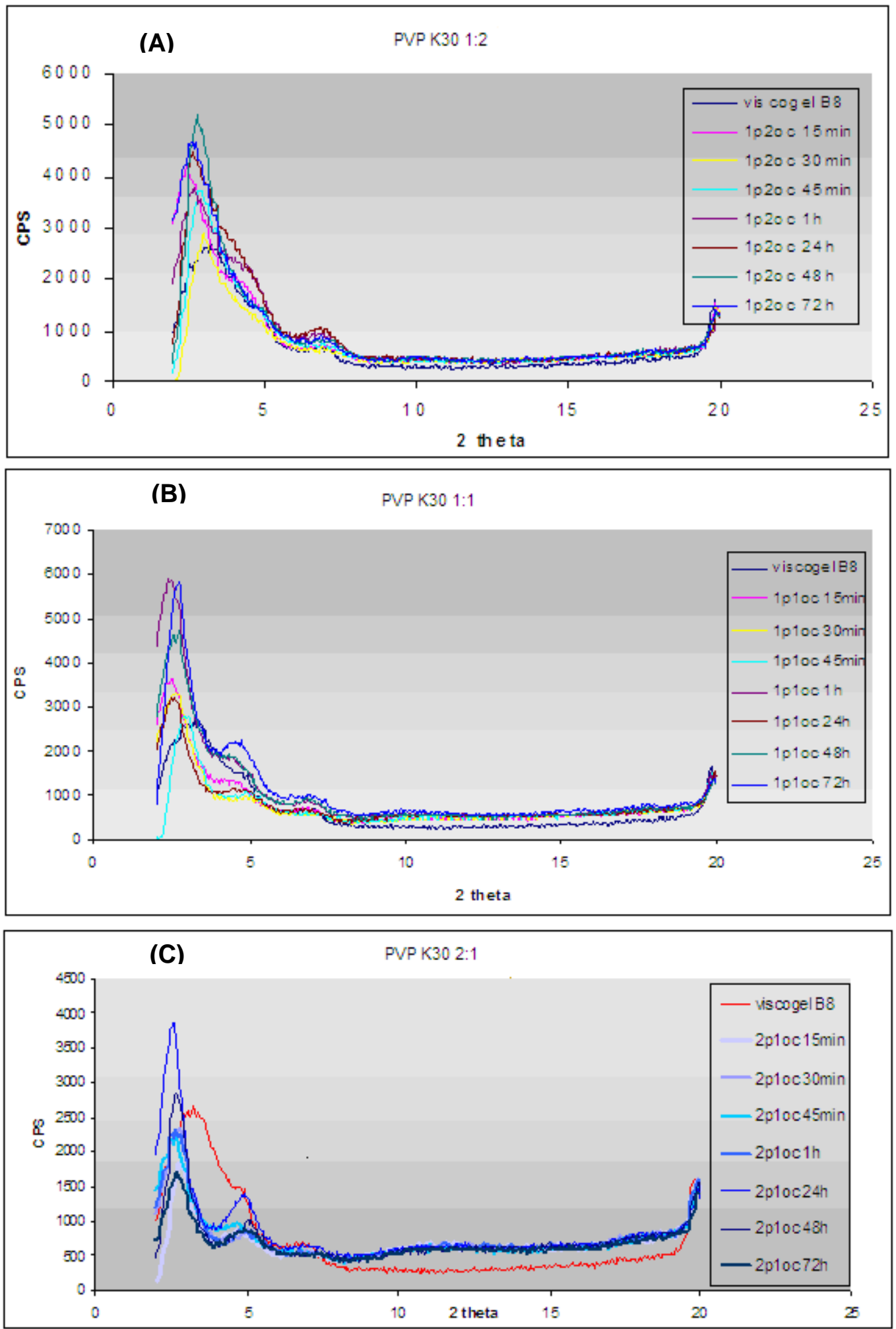

Figure 8. XRD of AAM/ PVP K-30 1:2 (A), 1:1 (B) and 1:2 (C) in different reactional times. 

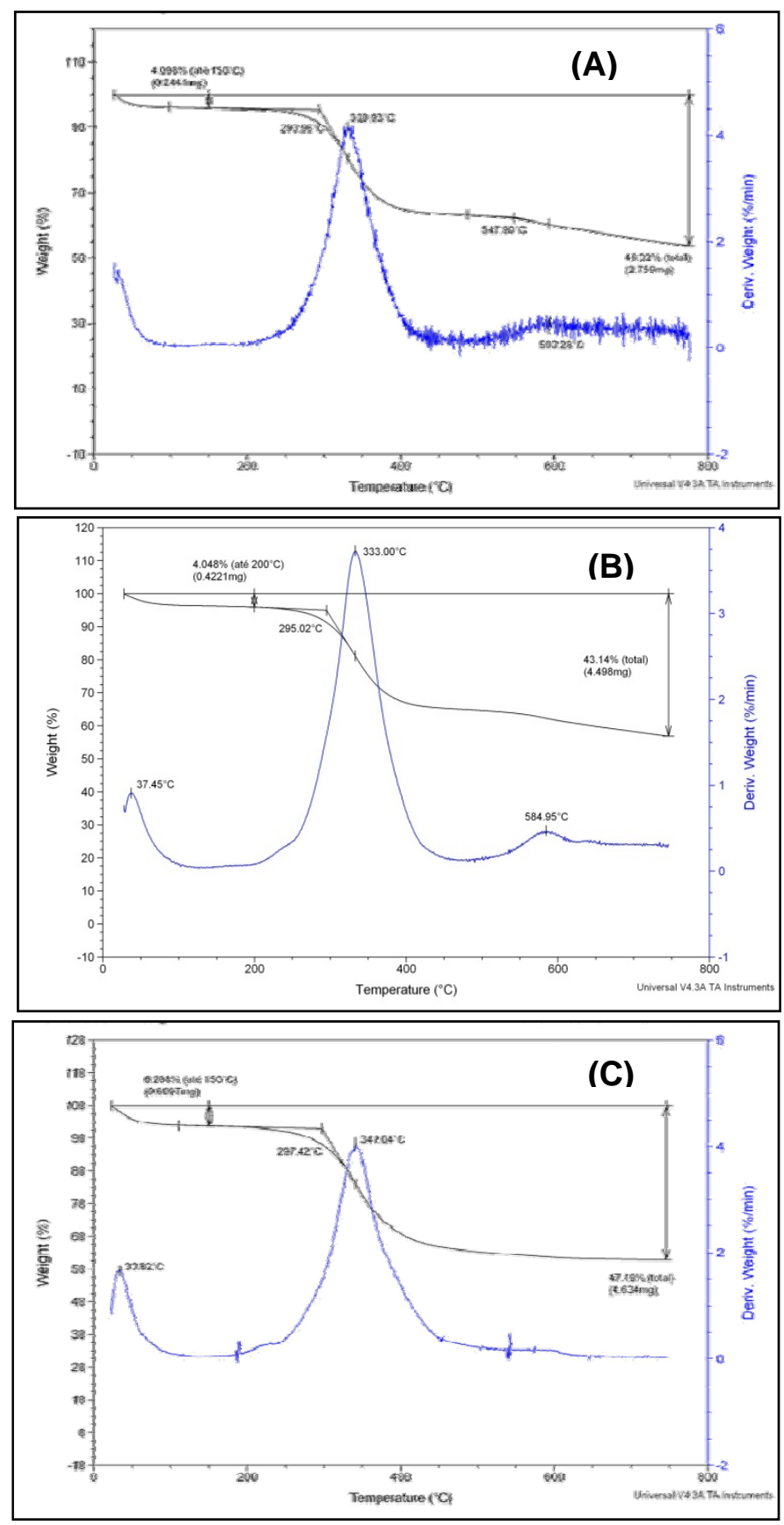

Figure 9. Thermogravimetric Analysis (TGA) of AAM/ PVP K-30 intercalation 2:1 (A), 1:1 (B) and 1:2 (C).

Thus, since the possibility of granulation with aqueous vehicles, slow release profile greater than the HPMC in lower concentrations and lower cost, the AAM presents as a promising new prolonged release lipophilic matrix.
A similar approach can be adopted for its nanocomposite with PVP, which can be further evaluated including their behavior as sustained release matrix for different drugs. 

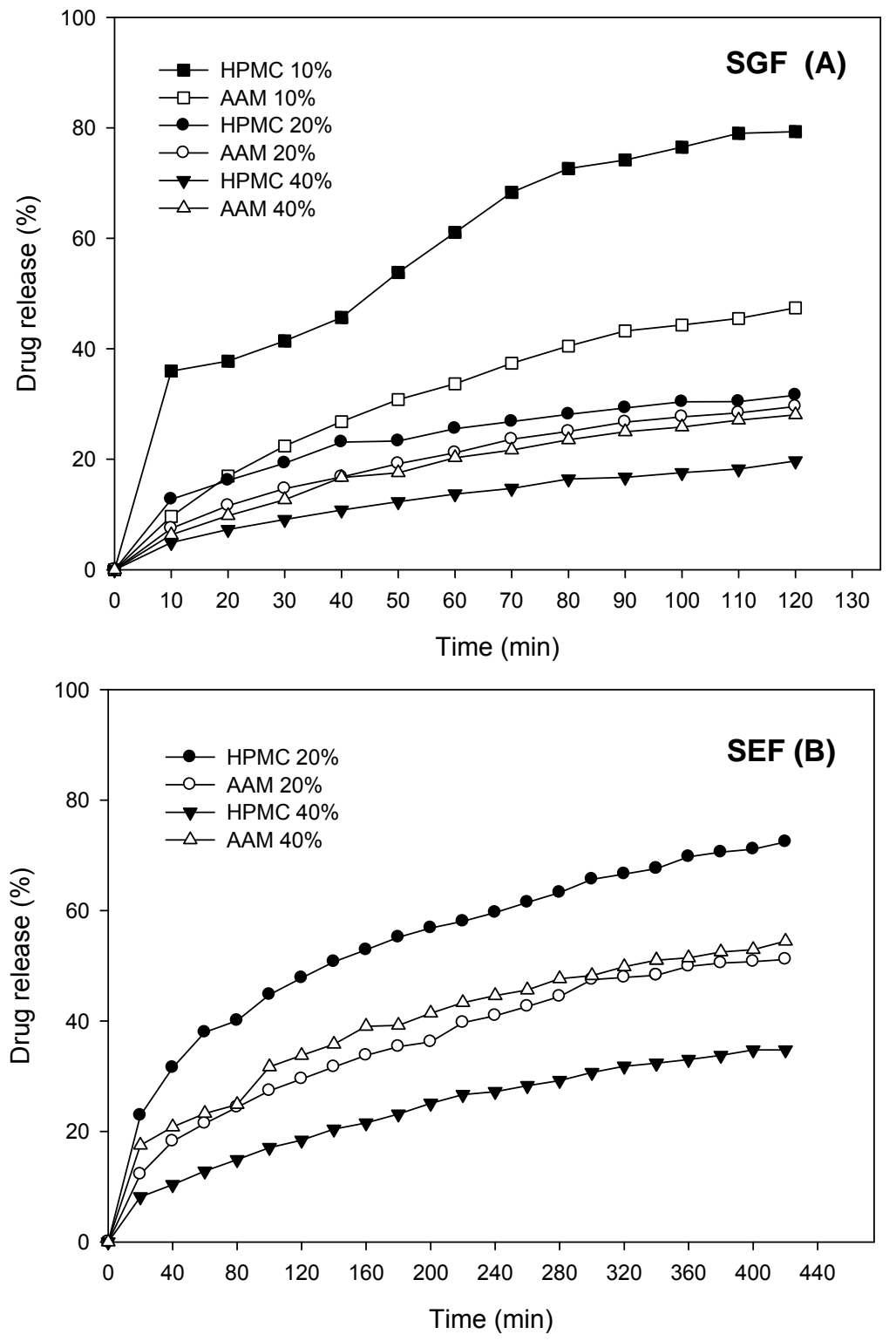

Figure 10. Dissolution profile of theophylline from HPMC and AAM matrix in different concentrations in the simulated gastric (SGF) (panel a) and in enteric fluids (SEF) (panel b).

\section{Evaluation of Nanocomposite AAM/ PVP K-30 as Dissolution Enhancer}

The evaluation of base formulation was performed with, and without dissolution enhancer using methyldopa as drug model, $3.0 \% \mathrm{w} / \mathrm{w}$ of crospovidone in the external phase as disintegrating (hardness $60 \mathrm{~N}$ ), and lactose in its internal phase. Methyldopa dissolution base formulation was extremely low (23.4\%) as expected for this drug, revealing the potential influence of the dissolution enhancers on the formulation. This study also investigated sodium croscarmellose, aerosil and sodium lauryl sulphate (SLS) as excipients in the internal phase of granulation at a concentration of $0.5 \% \quad \mathrm{w} / \mathrm{w}$ (22). For sodium croscarmellose insertion (hardness $58 \mathrm{~N}$ ) and aerosil (hardness 52 $\mathrm{N}$ ), the increase of dissolution of methyldopa was discrete $(35.0 \%$ for croscarmellose and $39.0 \%$ for the aerosil) producing tablets with no acceptable dissolution values (15). 


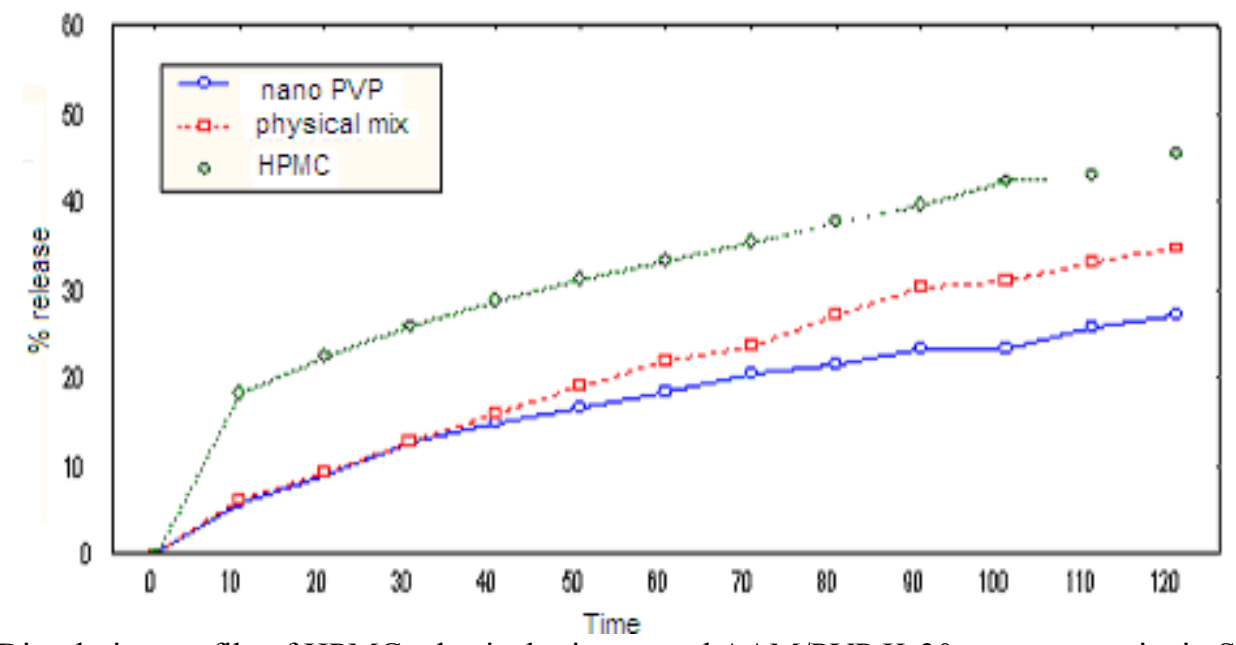

Figure 11. Dissolution profile of HPMC, physical mixture and AAM/PVP K-30 nanocomposite in SGF medium.

The use of SLS (hardness $56 \mathrm{~N}$ ) lead to the most effective drug dissolution increment (54\%). Importantly the dissolution values showed to be statistically different with $\mathrm{p}=0.0001$ in all assays. Herein we also studied the association of SLS and aerosil, both in the granulation internal phase at $0.25 \% \mathrm{w} / \mathrm{w}$ concentration each. These two excipients act by synergic and distinct mechanisms, thus, the dissolution enhancement increased water absorption and partial breaking of the crystallinity of the drug. The tablets dissolution assay containing silicate and surfactant (hardness $60 \mathrm{~N}$ ) led to $81 \%$ of drug release.

During the evaluation of the insertion of the new nanocomposite material $0.5 \% \mathrm{w} / \mathrm{w}$ in the methyldopa formulation at same conditions (hardness $69 \mathrm{~N}$ ), we observed approximately 88\% of drug dissolution, which is slightly higher than tablets containing silicate and surfactant $(p=$ 0.0032) and the pharmacopeic acceptable dissolution value.

\section{DISCUSSION}

The data from DSC and IV analysis and the XRD diffractogram of AAM are in concordance with the literature (Figure 2 and 3). The SEM analysis (Figure 4) pointed to the presence of the lamellar structure initially proposed (22). The tortuosity level of AAM related to its lamellar structure characterized this clay as a good sustained release matrix prototype (21). The AAM also demonstrated a low toxicity level as the results with animals is in accord to the System of Integrated Classification conciliated by Human Health related to the Exposition of Risk of Chemical Substances and Mixtures (22), that reports that AAM present no toxicity risks in a dose of $10000 \mathrm{mg} / \mathrm{kg}$ of body weight since this value is superior to the class five dose $(5000 \mathrm{mg} / \mathrm{kg})$.

The compactation characteristic of the AAM was studied and compared with HPMC, an excipient with excellent compression profile. Different compression forces give hardness values of AAM consistently greater than those of HPMC. These results showed that this material (AAM) is an excipient with ideal compactability and compressibility characteristics for tablets preparation. In addition the variation in the height and consequent reduction in volume detected for both matrixes were very small. These data suggest no significant differences between the porosity of each of those substances (24).

Nanocomposites using AAM/GME were prepared to intercalate lipophilic excipient on the AAM for sustained release purposes. This intercalation yield at the best condition reached up to $25 \%$, usual for lipophilic molecules intercalation (22).

Characteristics of swelling, increased tortuosity and zero order release kinetic profile may be obtained by combination of properties of the initial constituents to form a nanocomposite pharmaceutical excipient (25). 
Overall, it was detected the formation of a new nanomaterial in considerable yield, being proposed as substitute of lipophilic traditional matrices, such as carnauba wax or hydrogenated castor oil (26).

The dissolution results showed that AAM/GME nancomposite is not a suitable sustained release matrix. It was not observed delay using $40 \%$ of matrix in SGF or SEF medium, data not showed). So, it was investigated the substitution by a macromolecular substance with hydrophilic properties. The AAM/PVP K-30 nanocomposites were prepared based on different ratios of polymer and clay at different intercalation times, with ideal conditions observed for the $45 \mathrm{~min}$ for 2:1 mass rate system.

The nanocomposites were structured as expected due to the large volume occupied by the polymer mass. We observed an increase of the interlamellae spacing greater than $10 \AA$ in all experiments, noticing alkylammonium ion rearrangements between the clay lamellae. In agreement, the diffratograms suggested the formation of a nanocomposite. Moreover, apparently PVP K-30 was able to stabilize the monolamellae units by dipole-dipole binding probably due to its high affinity (22).

Our results showed no differences in yields or interlamellar spacing when performing different intercalation evaluations with pre-swelling clay, discarded the pre-swelling due to practicality and possibility of the operational time.

The TGA analysis results of the intercalated AAM/PVP K-30 did not show any increase of thermal stability of the nanomaterial. These analyses showed the same mass loss in all cases at the same temperature (27). Since the total removal of the intercalated octadecylamine in the clay was not evidenced, the material (a surfactant, octadecylammonium, a silicate portion, and a hydrophilic polymer with dissolution enhancer characteristics) was selected to perform the tests with methyldopa tablets and improve the dissolution profile.

The applicability of AAM and its nanoderivatives as sustained release matrix was verified using the dissolution assay of theophylline, a drug Class II of BSC. It was observed a lower initial burst effect for the AAM and its greater capacity for delay the drug release compared to HPMC. This result suggests that the concentration of $10 \%(\mathrm{w} / \mathrm{w})$ of this new excipient is sufficient to promote the expected drug release delay effect. Moreover, concentrations of $40 \%$ of AAM showed less efficiency in drug release delay compared to HPMC matrix. This fact could be associated to the minor swelling and greater erosion of the AAM in comparison to HPMC in higher concentrations. This remains as the main release control mechanism that leads to low release retention from the HPMC.

Based on these data, it can be concluded that the AAM is a new sustained release matrix with $20 \%$ as ideal concentration, better than HPMC. The dissolution profile in SEF showed no burst effect at $20 \%$ for AAM and HPMC, although $40 \%$ AAM decreases the efficiency of the drug release delay. This is probably due to the presence of high erosion in the basic medium, being AAM less effective than the HPMC at this concentration. Therefore concentration at $20 \%$ in weight is the ideal work concentration (28).

HPMC $20 \%$ presented $\mathrm{pH}$ susceptibility and more drug release compared to AAM, which is one of the advantage presented by this new matrix. Despite the concentration of $40 \%$ HPMC showed more efficiency in the delay of release, it could be out of the quantities to be used in practice, since it may hinder the total drug release.

In the release kinetic model evaluation for the AAM matrix, the zero and first order models were tested and as well as the exponential equation (Mt/ $M_{\infty}=K t^{n}$ ) and Higuchi proposal, to determine the most probable release kinetic of the active based on the new matrix (29). The results of the initial $60 \%$ of the theophylline release analysis in SGF and in SIF suggested a zero-order release kinetic, with the $\mathrm{n}$ exponent pointing to the prevalence of anomalous transport for the AAM (Table 6). The insertion of PVP K-30 inside the lamellas of the AAM may increase the swelling capacity of these materials, improving its performance as sustained release matrix.

The use of AAM/ PVP K-30 nanocomposite as sustained release matrix provided dissolution results in SGF superior to those obtained by using HPMC and $\mathrm{AAM}$ at $20 \%$ concentration. Similar results were observed with AAM/PVP K-30 physical mixture, pointing to the direct PVP influence in sustained release efficiency of new nanocomposite (Figure 11). 


\begin{tabular}{ccccc}
\hline Table 6. Drug release kinetic evaluation of the AAM newsustained release matrix \\
\hline \multirow{2}{*}{ Parameter } & \multicolumn{2}{c}{ First order kinetic } & \multicolumn{2}{c}{ Zero order kinetic } \\
\cline { 2 - 5 } & SGF & SEF & SGF & SEF \\
\hline (n) exponent & 0.752 & 0.714 & 0.793 & 0.824 \\
$\mathrm{R}^{2}$ & 0.9809 & 0.9700 & 0.9732 & 0.9698 \\
\hline
\end{tabular}

The nanocomposite AAM/PVP K-30 was evaluated as dissolution enhancer using methyldopa as model drug (class II of BSC) with low solubility. Probably due to the increase of water uptake by the tablets, the formulation developed using sodium lauryl sulphate (SLS) led to a most effective drug dissolution increment compared with using sodium croscarmellose and aerosil as disintegrating in the external phase, $(30,31)$. The association of SLS and aerosil in the granulated internal phase acts by synergic and distinct mechanisms, thus, the dissolution enhancement observed concerns to increase water absorption and partial breaking of the crystallinity of the drug.

The breaking of the drug crystallinity after the granulation with the silicate in the internal phase led to a superior dissolution of the drug confirming this association feasibility. The literature describes a similar behavior of breaking promotion in drug crystallinity through preparation of co-processed of different drugs with hydrophilic polymer, known as solid dispersions (32). A new promising association was identified by using surfactants and silicates as well as with the combination of these two excipients with hydrophilic polymers, based on our PVP results.
The use of different molar masses PVP as solid dispersion excipient is well described in the literature (32). Interesting, the PVP with curcumin produced a thermal alteration of this substance by DSC, pointing to a partial loss of crystallinity (33).

The proposal of solid dispersions formation by silicates is described by Porubcan (1978), which showed effective interactions of colloidal silicon dioxide and indomethacin complexes, confirming the material efficiency for enhancement of dissolution (34). Another silicate complex using sodium bentonite was obtained for the improvement of dissolution rate for different drugs (35).

The synergy of these mechanisms may be observed in the nanocomposite AAM formed by silicate containing octadecyl ammonium salt, a surfactant agent and with the PVP K-30, a polymer able to promote drug dissolution. The use of this new material in the methyldopa formulation gave slightly higher dissolution than tablets containing silicate and surfactant with an advantage of easy handling and processing of only one excipient, with drug amorphization in the methyldopa granulation observed by XRD (Figure 12).

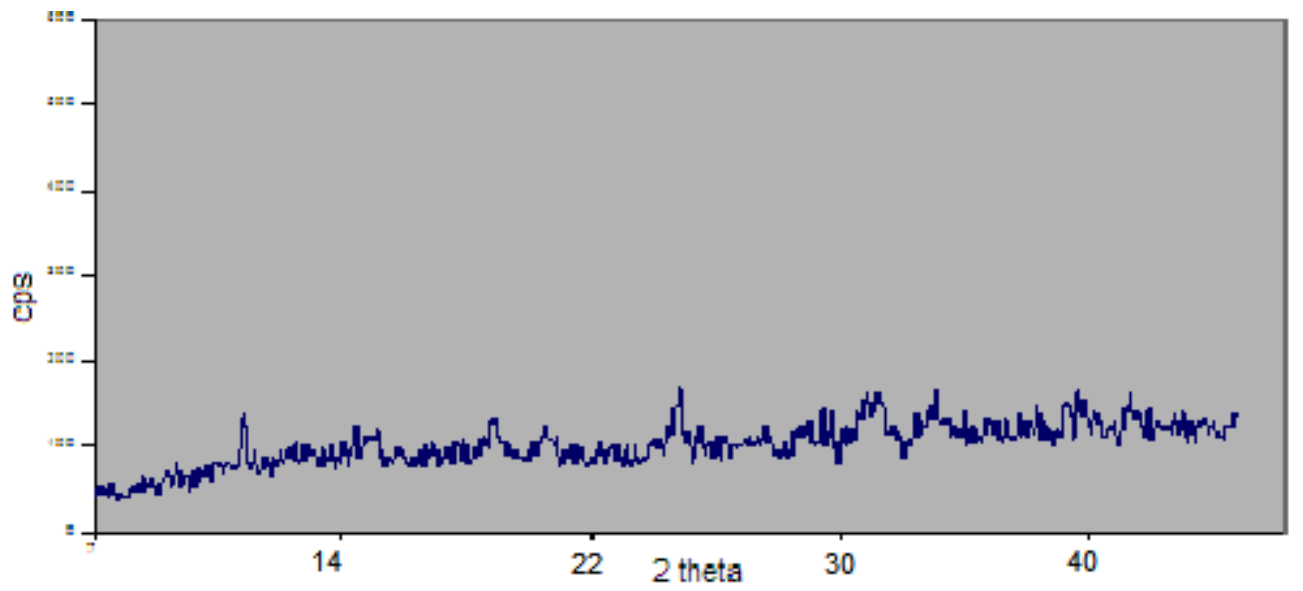

Figure 12. XRD of methyldopa granulation. 


\section{CONCLUSION}

In this work it was pointed the promising use of AAM (viscogel B8) and the new nanocomposite prepared by clay/PVP K-30 intercalation as a new matrix for sustained release. The results also suggested the feasibility of using these new nanocomposites as dissolution enhancer.

\section{ACKNOWLEDGEMENTS}

To the Membrane Laboratory (COPPE - UFRJ) and to LAPIN (IMA - UFRJ) for the analyses performed and CAPES Edital Nanobiotecnologia 2008, CNPq and FAPERJ for financial support.

\section{REFERENCES}

1. Soppimath KS, Aminabhavi TM, Kulkarni AR, Rudzinski WE. Biodegradable polymeric nanoparticles as drug delivery devices. J Control Release, 2001;70:1-20.

2. Lee SC, Ruegsegger M, Barnes PD, Smith BR, Ferrari M. Therapeutic nanodevices. In: Bhushan, B., The Nanotechnology Handbook, 2nd Ed, Springer-Verlag Heidelberg, German, pp 279-322, 2004.

3. Nijhara R, Balakrishnan K. Bringing nanomedicines to market: regulatory challenges, opportunities, and uncertainties. Nanomedicine 2006;2:127-36.

4. Bala P, Samantaray BK, Srivastava SK. Synthesis and characterization of Na-montmorillonitealkylammonium intercalation compounds. Mater Res Bull. 2000;35:1717-24.

5. Shah SS, Kulkarni MG, Mashelkar RA. pH dependent zero order released from glassy hydrogels: penetration vs. diffusion control. J Control Rel, 1991;15;121-32.

6. Chiou WL, Riegelman S. Pharmaceutical applications of Solid Dispersions. J Pharm Sci. 1971;60:1281-302.

7. Ebube NK, Hikal AH, Wyandt CM, Beer DC, Miller LG, Jones AB. Sustained release of acetaminophen from heterogeneous matrix tablets: influence of polymer ratio, polymer loading and coactive on drug release. Pharm Dev Technol. 1997;2:161-70.

8. Chien YW. Fundamentals of controlled-release drug administration. In: Novel Drug Delivery Systems: Fundamentals, Development Concepts, Biomedical Assessments, Marcel-Dekker, New York. pp. 43138, 1982.

9. Chambin O, Champion D, Debray C,; RochatGonthier MH, Le Meste M, Pourcelot Y. Effects of different cellulose derivatives on drug release mechanism studied at a preformulation stage. $\mathrm{J}$ Control Release 2004;95:101-8.

10. Amidon GL, Merfeld AE, Dressman JB. Concentration and $\mathrm{pH}$ dependency of $\alpha$-methyldopa absorption in rat intestine. J Pharm Pharmacol. 1996;38:363-8.

11. Siepmann J, Peppas NA. Modeling of drug release from delivery systems based on hydroxypropyl methylcellulose (HPMC) Adv Drug Deliver Rev. 2001;48:139-57.

12. Leuner C, Dressman J. Improving drug solubility for oral delivery using solid dispersions. Eur J Pharm Biopharm. 2000;50:47-60.

13. Schiermeier S, Schmidt PC. Fast dispersible ibuprofen tablets. Eur J Pharm Sci. 2002;15:295305.

14. United States Pharmacopoeia 31 and National Formulary 26. Rockville, MD: United States Pharmacopoeia Convention, 2008.

15. Rembischevski P, Gemal AL. Determination of the Influence of Borate Ion on the degradation of $\mathrm{L}-\alpha-$ methyldopa using RP-HPLC with photodiode array detection. J Liq Chromatogr Relat Technol. 2001; 24:2661-2671.

16. Talukdar MM, Kinget R. Swelling and drug release behavior of xanthan gum matrix tablets. Int $\mathrm{J}$ Pharm. 1995;120:63-72.

17. United States Pharmacopoeia 31 and National Formulary 26. Rockville, MD: United States Pharmacopoeia Convention, pp. 3374-3375, 2008.

18. United States Pharmacopoeia 31 and National Formulary 26. Rockville, MD: United States Pharmacopoeia Convention, pp. 2675, 2008.

19. Lee PI. Kinetics of drug release from hydrogel matrices. J Controlled Release 1985;2:277-28,

20. Sun CQ, Zhou DL, Grant DJW, Young VG. Characterization of Crystalline PhaseTransformations in Theophylline by Time-Domain Terahertz Spectroscopy. Acta Crystallogr., Sect. E: Struct. Rep. Online 2002, 58, O368.

21. Gurina GI, Savchenko KV. Montmorillonite intercalation complexes and their interaction with epoxy compounds. Theor Exp Chem. 1994;29:6365.

22. NHI. The Up-and-Down Procedure: Peer panel Report. In: The Revised Up-and-Down Procedure: A Test Method for Determining the Acute Oral Toxicity of Chemicals. NICEATM-ICCVAM, pp. I$4,2001$.

23. Simon S, Cerf DL, Picton L, Muller G. Adsorption of cellulose derivatives onto montmorillonite: a SEC-MALLS study of molar masses influence. Colloids Surf A Physicochem Eng Asp. 2002;203:77-86.

24. Takeuchi H, Nagira S, Yamamoto H, Kawashima Y. Die wall pressure measurement for evaluation of 
compaction property of pharmaceutical materials. Int J Pharm. 2004;274:131-8.

25. Velasco MV, Muñoz A, Jiménez-Castellanos MR, Castellano I, Goñi I, Gurruchaga M. In vitro evaluation of sustained-release matrix tablets prepared with new modified polymeric carbohydrates. Int J Pharm. 1996;136:107-15.

26. Rowe RC, Sheskey PJ, Owen SC. Handbook of Pharmaceutical Excipients. 5 ed. Pharmaceutical Press, Great Britain, 2006.

27. Xie W, Gao Z, Pan WP, Hunter D, Singh A, Vaia R. Thermal Degradation Chemistry of Alkyl Quaternary Ammonium Montmorillonite. Chem. Mater. 2001;13: 2979-90.

28. Katikaneni PR, Upadrashta SM, Neau SH, Mitra AK. Ethylcellulose matrix controlled release tablets of a water-soluble drug. Int J Pharm. 1995;123:11915.

29. Siepmann J, Peppas NA. Modelling of drug release from delivery systems based on hydroxypropyl methylcellulose (HPMC). Adv Drug Deliv Rev. 2001;48:139-157.
30. Abdou, HM. The Science and Practice of Pharmacy. 20 ed. Lippincott Williams \& Wilkins, Philadelphia, USA, 2000.

31. Khan MZI. Dissolution testing for sustained or controlled release oral dosage forms and correlation with in vivo data: challenges and opportunities. Int $\mathbf{J}$ Pharm. 1996;140:131-43.

32. Craig, DQM. The mechanisms of drug release from solid dispersions in water-soluble polymers. Int $\mathrm{J}$ Pharm. 2002;231:131-44.

33. Paradkar A, Ambike AA, Jadhav BK, Mahadik KR. Characterization of curcumin-PVP solid dispersion obtained by spray drying. Int $\mathrm{J}$ Pharm. 2004;271:281-6.

34. Porubcan LS. Mechanism of adsorption of Clindamycin and Tetracycline by Montmorillonite. J Pharm Sci. 1978;67:1081-7.

35. Mc Ginity JW, Harris MR. Influence of a Montmorillonite Clay on the Properties of Griseofulvin Tablets. Drug Dev Ind Pharm. 1980;6:49-59. 